\title{
ATENEA: HEMEROGRAFÍAS*
}

\author{
SERGIO VERGARA ALARCÓN**
}

$\mathrm{U}$

N estudio PIONERo del filósofo Jürgen Habermas, de la segunda generación de la escuela de Frankfurt, publicado en LuchterhandVerlag (1962) bajo el título Strukturwandel der Öffentlichkeit, cuya edición en español, en Gustavo Gili, reza: Historia y crítica de la opinión pública. La transformación estructural de la vida pública, es una investigación que aborda áreas de la politología, sociología, economía, y de la historia de las ideas. Otra traducción, en rigor, literalmente debería ser: Cambio de estructura de la opinión pública. En el ensayo se estipulan los inicios de lo que se va a llamar la crítica cultural, la crítica de arte, las notas científicas y culturales en general, que se publicaban en diarios, periódicos, anales, boletines, magazines, estampas, códices, apuntes, gacetas, cuadernos, folletines, y que constituyen, en amplio espectro, el surgimiento de la hemerografía (del griego hemero-grafos = tratado del día), decisivas instancias mediatizadoras para lo que se va a denominar la "guía del gusto" o con vistas a la "educación del gusto". Los escritos hemerográficos han sido, en principio, definidos por su periodicidad, regularidad y la frecuencia de su secuencia.

En el siglo XVII y XVIII se desarrolla la comercialización del libro. Se crea un mercado de libros y ello implica la correspondiente institucionalización de la crítica literaria y la profesionalización del escritor. Con ello, se ampliaba el espectro de lectores, según la acertada taxonomía de Harald Weinrich, entonces surge el lector extensivo: más lectores leen más libros. Entonces, debe instalarse un principio selectivo en el ámbito de la oferta creciente de la cultura ilustrada.

Un hito notable del surgimiento de la crítica de arte y cultura en general, lo constituyen los Salonberichte, que traducimos libremente como "informes de salón", de Diderot.

\footnotetext{
* Texto leído con ocasión del lanzamiento de Atenea 518, Universidad de Concepción, 4 de abril de 2019.

** Doctor en Hispanística. Académico de la Universidad de La Serena, La Serena, Chile. Correo electrónico: svergara@userena.cl
} 
Así y como documentos de producción y a la vez de recepción de textos, entran al circuito de distribución y consumo, fijan un canon de obra, ofrecen opciones axiológicas y determinan formas históricas de lecturas. En la mayoría de los casos, los ejercicios teóricos giran en torno a la historia de la "idea de la literatura", mediatizada por las instancias críticas, en la forma de una metahistoriografía o metacrítica.

Las revistas literarias y culturales en general forman parte de los sistemas intermediarios funcionalizados por la Institución Arte (Institución Ciencia). La Institución literatura (Arte) se apoya en instituciones oficiales que organizan, funcionalizan, y ponen a disposición sistemas intermediarios sobre la base de los cuales opera su papel de "vigilancia" y control. Sus tareas son: a) su imparcialidad (un proyectado objetivismo), b) la capacidad de tomar decisiones en cuanto a la selección, producción, orientación y control de los sistemas comunicativos reales y c) la capacidad de hacer reconocibles, a través de diversos mecanismos, el estatus de "literario" o "artístico" de esos productos.

El concepto de "Institución Arte" debe entenderse tal como se constituye en la sociedad burguesa, como el aparato institucional de producción de arte y al mismo tiempo, las concepciones vigentes (afirmadas por la propia institución) en una época dada en torno al arte, conceptos estos que determinan esencialmente la recepción de obras artísticas. Estas instancias mediatizadoras son, entre otras, los agentes literarios, los consejos de redacción, consejos consultivos, los archivos literarios, las academias de la lengua, los premios literarios, las sociedades, agrupaciones literarias y artísticas, etc. De allí que sea necesario reconstruir ese corpus hemerográfico, para actualizar todas las instancias participantes en este diálogo contextual, incluida, claro está, la recepción crítica.

Este proceder editorial que exige ante todo una tarea de orden estrictamente filológico, documental, permite observar cómo se ordenaban los sistemas de inclusiones y exclusiones o cómo los discursos dialogaban en tanto dominantes y cuáles eran promovidos por la Institución Arte.

Su afán, como el de toda revista, es el de sentar un canon pragmático y cristalizarlo en casos textuales y genéricos específicos. La creación de una revista no quiere inscribirse en una serie textual, si no es negándola por su ocupación de un lugar diferencial. Por lo demás, la revista actúa en el presente inmediato y opera coyunturalmente; por ello tiene una vigencia diacrónica muy distinta a la que tiene un libro, el cual puede ser recepcionado productivamente a mediano y largo plazo. La revista sirve inmejorablemente como documento actualísimo de las expectativas contextuales 
que quiere satisfacer y realiza una suerte de "política cultural". La misma aproximación del crítico a la revista es una operación más arqueológica que la del mismo receptor frente a un libro.

El horizonte de expectativas se entiende como el conjunto de reglas de juego con que el lector ha sido familiarizado a través de géneros literarios o clase de textos, lo que le permite concebir un texto literario o artístico en tanto tal, y lo lleva a "esperar" la concreción de una concepción prefijada respecto de lo que la literatura y el arte deberían ser.

En retrospectiva, en el año 1729, en el Hallenser Intelligenz Blatt se lee que los sabios (profesores de las facultades de derecho, medicina y filosofía) podrán enviar a la dirección del periódico notas claras para participar al público "verdades susceptibles de aplicación", lo que deberíamos entender como forma de raciocinio ilustrado. Con ello, en la evolución y formación de la así llamada opinión pública, la conversación deviene crítica y "las agudezas y ocurrencias", argumentos. Entonces, el desplazamiento se da desde el amateur éclairés al "juez de arte". Al decir de Étienne La Font: "la exposición de un cuadro es un libro dado a la luz de la imprenta, es una pieza representada en el escenario -cada ser humano tiene el derecho de juzgar aquello".

A propósito, Habermas agrega: "Los museos, como un concierto, como el teatro, institucionalizan el juicio sobre el arte y de allí la discusión se convierte en un medio para su apropiación".

Así, de esta manera, surge la crítica profesional de arte que debe procurarse su audiencia a través de los escritos periodísticos y de las instancias hemerográficas también citadas.

Para mencionar un caso ibérico y mediterráneo; en 1884, Leopoldo Alas había publicado dos libros de crítica: La literatura en 1881 y los Solos. Con ello se había inaugurado la crítica independiente en España.

El año es 1924, en la Universidad de Concepción, el connotado rector don Enrique Molina Garmendia funda la revista Atenea que hoy celebramos en su número 518 después de la prolongada experiencia de 92 años, descontados los años 69 y 71, en los cuales la revista no se editó.

Observemos ahora algunos paratextos que, definidos rudimentariamente, son "accesorios" que se sitúan en una zona indeterminada entre la periferia o el rededor y el texto mismo, en este caso, nuestra revista.

El azar con sentido que nos enseña Nietzsche me lleva al ejemplar número 378 de octubre-noviembre-diciembre de 1957. En tanto efeméride o "memorial" se consignan las noticias de la muerte de Gabriela Mistral, 
de Diego Rivera, año en que se otorga el Premio Nacional de Literatura a Manuel Rojas (allende los Andes, el autor del prodigioso Aleph obtiene el Premio Nacional de Literatura). En el mismo número que consultamos, en "Puntos de vista" (Arte y literatura), leemos: "Las ciudades se alzan bulliciosas robando espacio a los cielos, y, en medio de ellas, los hombres se enfilan afanosos para subsistir".

En otra parte:

El hombre tiene hoy día puesta su mirada en las perspectivas infinitas de la investigación y descubrimiento científicos, tan abiertas de porvenir, que el pasado, con toda su carga histórica, apenas si cuenta, considerado por muchos como una rémora que atasca este rápido y constante proceso de dominio técnico. Deslumbrado por todo ello, el hombre-masa vive el instante presente, pues su imaginación no le permite avizorar más allá de lo concreto y factible, ni menos detenerse a contemplar la trayectoria de la humanidad, formada por una concatenación interminable de sucesos como eslabones de una cadena sin fin. Pues los actuales descubrimientos de la ciencia son el resultado de vigilias y atisbos de incontables generaciones.

En la solapa del número 109 de 1934, leemos:

Atenea inició su publicación en 1924 y la ha continuado hasta la fecha con absoluta regularidad. En los 10 números que ha editado anualmente hasta 1930 inclusive en los 12 números que edita desde este año, trata de dar una visión completa y siempre actual de las actividades espirituales chilenas y americanas en primer lugar y luego de las de otros países del mundo.

El amplio espectro de sus intereses se observa en las bajadas: "Revista mensual de ciencias, letras y artes"; "Revista de ciencia, humanidades y arte"; "Ciencia, arte y literatura" y hoy: "Revista multidisciplinaria semestral de la Universidad de Concepción".

En el número 378 del año 1957. Leemos en la portada:

Atenea

Revista trimestral de Ciencias, Letras y Artes publicada por la Universidad de Concepción (Chile)

Sumario

Los libros - Glosas de la cultura - Crítica de arte - Notas y documentos

- Bibliografía - Índice general 
Y en la solapa:

Fundador: Enrique Molina Garmendia.

Rector honorario vitalicio de la Univ. de Concepción

Comisión Directora: David Stitchkin Branover - Avelino León Hurtado

- Félix Armando Núñez.

Representante de la Dirección en Santiago: Milton Rossel.

En el número 378, que consultamos, en la sección Notas y documentos, se lee: "Cuarta Escuela Internacional de Verano de la Universidad de Concepción", plan de extensión cultural de afamada memoria especialmente dada la programación de jornadas de literatura, filología y gramática, entre otras. Uno de los apartados se titula: Situación de la literatura chilena en 1958, presentación de veinte escritores chilenos invitados por la Universidad de Concepción, a cargo de los profesores señores Gonzalo Rojas, Alfredo Lefebvre, Daniel Belmar, Juan Loveluck.

Junto con otras revistas de connotación continental, por ejemplo, Arbor, Repertorio americano, Sur, Revista de Occidente, Aurora de Chile, Mandrágora, Amauta (estas dos últimas entre las fugaces), Atenea ha marcado las rutas continentales del saber que hoy llamaríamos des-trans-interdisciplinarios; y, de modo visionario, ha cubierto territorios oscilantes de esta cultura.

Atenea ha sido reconocida como una de las referencias obligatorias en el marco de la investigación, de la producción del saber, de la academia, en la hispanística, también en Europa (la colección completa de Atenea se encuentra en la biblioteca del Instituto Iberoamericano de Berlín, República Federal de Alemania), donde se atesoran otras revistas nacionales como Mandrágora.

Como toda revista, Atenea permite a través de su índice inferir e inteligir los criterios plurales de un presente, el censo de las preferencias disciplinarias, los topoi abordados en una época, los intereses heteróclitos de ese presente, y constituyen intentos de fijación histórica para las prospectivas.

Nosotros, sus lectores, aprendimos como párvulos griegos, despacio, oteando, y en cada bibliografía había que citar, cosa necesaria, nuestra revista. Ella ha sobrevivido a las exigencias de la así llamada "universidad tecnocrática", altamente escolarizada, y cada vez más vigilada y castigada; Atenea ha podido resistirse gracias a la dignidad de su trayectoria.

Si al decir de Hegel: "el búho de Minerva emprende el vuelo al atardecer”, la revista Atenea alcanzó su acmé, su maduración vigorosa, y no se 
detendrá, esperamos, dado el juicio, el esfuerzo y la inteligencia probada de mi Alma Mater. Deseamos que este búho de Minerva, la magnánima, sea el magnífico testimonio para los tiempos del desarrollo libre del espíritu.

\section{REFERENCIAS}

Dresdner, A. (1915). Die Enstehung der Kunstkritik im Zusammenhang des europäischen Kunstlebens. München, Alemania: F. Bruckmann A.-G.

Habermas, J. (1990). Strukturwandel der Öffentlichkeit. Frankfurt am Main, Alemania: Suhrkamp.

Muñoz, L. (1991). Lectura y lectores en El Quijote. Acta Literaria, 16, 3-19. 